\title{
New Media Literacy And Media Use Among University Students In Malaysia
}

\author{
Chin Ying Shin, Hasmah Zanuddin.
}

\begin{abstract}
False information is a concern in this digital era where communication technologies, particularly social media, enable the public to consume, create, and share media content. New media literacy associated with critical thinking is of importance in keeping away from the negative influences of the widespread misleading news and information. Due to the limited studies on new media literacy in Malaysia, this study aimed to identify the levels of new media literacy among university students in Malaysia, measure the difference in new media literacy across demographic factors, and examine the relationship between media use and new media literacy. The quantitative data were collected through survey questionnaire at a private university in Malaysia. The findings showed that most of the students are at the medium level of new media literacy. No significant difference was found in new media literacy based on demographic factors, except media use which also had a small positive correlation with two dimensions of new media literacy, namely functional prosumption and critical prosumption. The findings served as a valuable input for public or private institutions or organizations that are responsible or keen in tackling fake news.
\end{abstract}

Index Terms: New Media Literacy, Functional Consumption, Critical Consumption, Functional Prosumption, Critical Prosumption, Media Use

\section{INTRODUCTION}

Technology has changed the way people consume information, a lot of them rely on Internet to seek for news and entertainment [1]. Most of the young people visiting social media through mobile phones are surrounded by abundance of news content on social media feeds, and even exposed to incidental news that they are not purposely looking for [2]. According to Digital News Report 2018 by Reuters Institute for the Study of Journalism, Facebook (64\%) and WhatsApp (54\%) were the top two platforms of news consumption in Malaysia, the country also appeared as the highest news consumption on WhatsApp globally [3]. The convenience that media offer to people in news consumption can affect and change people's perception of reality and the worldview, therefore media literacy is an important skill that young people should have in this digital age $[1,4]$.

Revised Manuscript Received on April 19, 2019.

Chin Ying Shin, Department of Media and Communication Studies, Faculty of Arts and Social Sciences, University of Malaya, Kuala Lumpur, Malaysia.

Hasmah Zanuddin, Department of Media and Communication Studies, Faculty of Arts and Social Sciences, University of Malaya, Kuala Lumpur, Malaysia.
False information emerged before the rise of the Internet, however some content publishers or creators nowadays can spread misleading information for personal gain, through social media, more easily $[5,6]$ which will leave impacts not solely on teenagers but also on adults, particularly university students [7]. Media literacy which enables people to understand the meaning construction from media messages, identify message creators as well as differentiate content that comprises of bias, lies, and misinformation [4] plays an important role in this scenario. Past study also showed that people with higher level of media literacy are more capable in analyzing media with critical thinking [8].

The level of new media literacy was found medium among the university students in Turkey, the longer time they spend on the Internet, social media, and blogging, the higher the level of media literacy [9], however university students in Lebanon who are social media and Internet savvy were found lack of the ability to evaluate and differentiate the trustworthiness of media content [7]. This shows that new media literacy level varies among university students across different countries, which subsequently poses a question on the new media literacy level among university students in Malaysia. Despite some past studies in relation to media literacy had been conducted in the local context $[10,11]$, new media literacy based on the framework of Chen, Wu, and Wang [12] has so far never been studied in the same context. Therefore, grounded on the new media literacy framework, this study aims to examine the new media literacy level among university students in Malaysia, measure the difference in new media literacy across demographic factors, and examine the relationship between media use and new media literacy.

\section{LITERATURE REVIEW}

\section{A. New Media Literacy}

The concept of media literacy has long existed in the Western countries such as UK and Australia, however it was only promoted in East Asia in the last decade of the 20th century [13]. Media literacy has been defined differently in the past studies. It broadly refers to the "ability of a citizen to access, analyze, and produce information for a specific outcomes [14]." Buckingham [15] defines the term as the 
ability to access, understand, and create communications in different contexts. Literat [16] further explains that media literacy can be applied in both traditional (print media, television, radio) and new media (Internet, video games, mobile telephony). When new media technology is changing media landscape, new media literacy emerged and has been the focus of many scholars. In order to participate in new media environment, people need to be new media literate [12] especially in coping with abundance of information on new media.

Potter [17] posed three questions after reviewing many definitions of media literacy developed by past scholars since 1971. First, what are the media that the scholars refer to when considering the idea of media literacy? Across many studies in the past, certain medium is focused in different studies, Potter [17] mentioned the need to look at all forms of media when studying the idea of media literacy. Second, what do we mean by literacy? Potter [17] found that some scholars perceive literacy as skills, knowledge, activity and so on, and he himself also developed the fundamental knowledge structures which include media effects, media content, media industries, the real world, and the self that serve as the foundation of media literacy [18]. Third, what should be the purpose of media literacy? He found that most of the definitions are complementing each other rather than criticizing on the best definition, eventually the main ideas of media literacy appeared to be generally agreed on whereas other than the main ones were generally accepted.

There are four common themes pertaining to media literacy identified based on the past studies [17]. First, the mass media are regarded as having potential to bring potentially negative impacts to the people. Second, media literacy is aimed to assist people to keep themselves away from the potentially negative impacts. Third, media literacy must be developed. Media forms and messages keep changing constantly; no one will be completely media literate as there is no ending in the long term process of knowledge seeking and skills development. Fourth, media literacy has different dimensions. People can be directly or indirectly influenced by media in terms of cognitive, attitude, emotion, physiology, behavior. For example, one can be emotionally affected by a movie although the he or she is analytical in the cognitive dimension [17].

\section{B. New Media Literacy Dimensions}

As media literacy is characterized as multi-dimensional, Buckingham [15] identified three dimensions which are access, understand, and create. Chen, Wu [12] proposed another set of dimensions of media literacy based on two continuums from criticality to functionality and from consumption to prosumption. Based on the preliminary framework by Chen, $\mathrm{Wu}$ [12], functional media literacy is interpreted as understanding the messages or content in the media, it also includes operating media tools and producing media content. It is not holistic to understand new media literacy solely from the functional aspect, the critical aspect should be considered as it covers analyzing, evaluating, and critiquing media, it involves an understanding of both textual and social meanings of the media content, the social values, purpose of the media producers as well as the power position of the media producers and audience.
The four dimensions of new media literacy framework were identified, namely functional consumption, critical consumption, functional prosumption, and critical presumption [12] as shown in Figure 1. According to Chen, $\mathrm{Wu}$ [12], functional consumption refers to the ability of individuals in accessing and understanding media content; critical consumption means the ability of individuals who not only understand the messages but are also able to interpret and

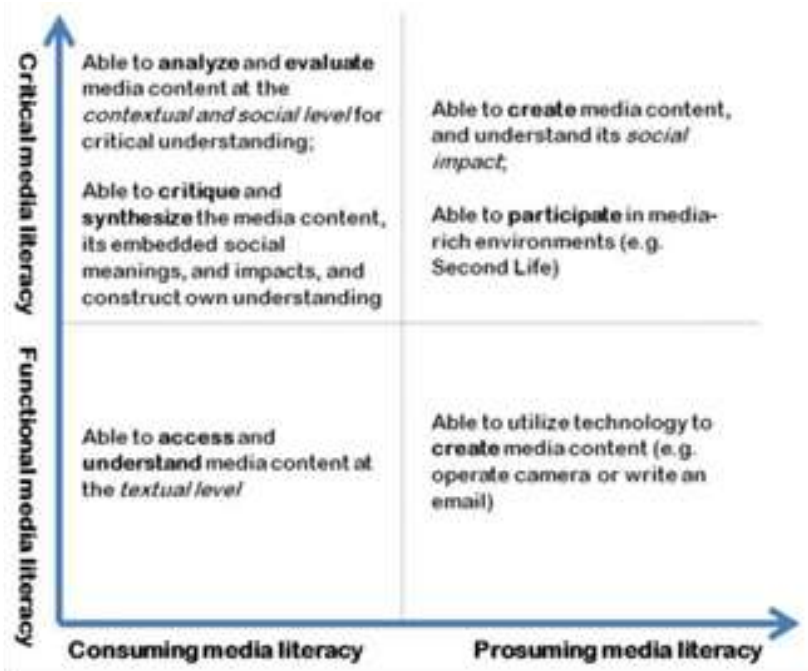

Figure 1: New Media Literacy Framework [12]

judge them in a critical way; functional prosumption is defined as individuals can produce media content on any new media platform; critical prosumption means individuals know their position in media participation, construction and publication, in other words, individuals can create media content apart from consuming it [12].

\section{New Media Literacy, Demographic, and Media Use}

Media literacy is associated with youth positive development and empowerment, young people who consume news regularly tend to be more careful and critical in consuming media content, as well as more likely involved in civic engagement [19]. When they join pro-social activity, they are also more able to take part in deliberation, and also produce and share media content using different technologies [20].

Some researchers used a set of new media literacy skills identified by Jenkins, Clinton [21] in their studies. The twelve new media literacy skills included play, simulation, performance, appropriation, distributed cognition, multitasking, collective intelligence, judgment, transmedia navigation, networking, negotiation, and visualization. Based on the skills, Miocic and Perinic [22] found that males in Zadar were more new media literate in terms of performance and appropriation, whereas females were shown better in collective intelligence, multitasking, and visualization. In Serbia, Arsenijević and Andevski [23] found that male was not only more new media literate in performance and appropriation as in Zadar, but also scored better in other new media literacy skills such as negotiation, 
appropriation, and distributed cognition. However, gender was no significant difference in new media literacy skills in Turkey [9].

In terms of age, although no significant difference in new media literacy skills was found in Zadar [22], but younger people in Serbia and Turkey show higher new media literacy skills than their counterpart $[9,23]$. Thus, this study proposes the first research question with two hypotheses as follows:

RQ1: Is there any difference in new media literacy across demographic factors?

H1: Males show higher new media literacy level than females.

Table 1: Reliability Test of Scales

\begin{tabular}{lcc}
\hline & $\begin{array}{c}\text { Cronbach's } \\
\text { Aplha }(\mathrm{n}=20)\end{array}$ & $\begin{array}{c}\text { Number } \\
\text { of items }\end{array}$ \\
\hline Media Use & .882 & 17 \\
Functional Consumption & .751 & 7 \\
Critical Consumption & .735 & 11 \\
Functional Prosumption & .772 & 7 \\
Critical Prosumption & .787 & 10 \\
\hline
\end{tabular}

$\mathrm{H} 2$ : Younger respondents show higher new media literacy level than the older respondents.

Past studies showed that longer time spending on new media consumption was associated with higher new media literacy. Measuring using the same new media literacy skills [21], Balaban-Sali [9] found that longer time spent on watching television and digital game was significantly associated with higher play skills; longer time spent on blogging had higher simulation skills than those who showed no interest in blogging; longer time spent on Internet and social media had higher performance skills. Literat [16] who studied the relationship between new media literacy and exposure to media also found consistent results. She discovered new media such as Internet and videogames use had a significance difference in media literacy, whereas traditional media (television and print media) showed no significant difference. Besides, Facebook, Twitter, Youtube, and blogging use also had strong positive correlation with media literacy levels. This is supported by Miocic and Perinić [22] where they found similar findings in the context of Zadar. Based on the literature, this study proposes the second research question with two hypotheses.

RQ2: Is there any relationship between media use and new media literacy?

H3: There is a significant difference in new media literacy by media use.

H4: There is a positive relationship between media use and all dimensions of new media literacy.

\section{METHODOLOGY}

\section{A. Participants}

As a preliminary research, survey questionnaires were distributed to 130 university students aged 18 to 25 at Universiti Tunku Abdul Rahman, a private university located in Perak, Malaysia. Of the total questionnaires, only 128 sets were usable as two sets were incomplete. Respondents were approached through convenient sampling method. In the sample, $51(39.8 \%)$ were male and 77 $(60.2 \%)$ were female. As for age distribution, 85 (66.4\%) respondents were aged 18 to 21 (younger group), whereas $43(33.6 \%)$ respondents were aged 22 to 25 (older group).

\section{B. Measures}

The questionnaire consists of three sections. The first section asked for demographic information. Second section measured media use of the respondents, the scale was adapted from Rosen, Whaling [24], 10-point frequency scale $(1=$ Never to $10=$ All the time $)$ was used the measure media use, items included were "post photos on Facebook", "search the

Table 2: New Media Literacy Levels

\begin{tabular}{lcc}
\hline \multicolumn{1}{c}{ Media Literacy } & Frequency & Percent (\%) \\
\hline Low & 8 & 6.3 \\
Medium & 79 & 61.7 \\
High & 41 & 32 \\
Total & 128 & 100 \\
\hline
\end{tabular}

Table 3: T-test Results Comparing Gender and Age on New Media Literacy

\begin{tabular}{lcccc}
\hline \multirow{2}{*}{ Demographics } & \multicolumn{4}{c}{ New Media Literacy } \\
\cline { 2 - 5 } & $\mathrm{M}$ & $\mathrm{SD}$ & $\mathrm{t}$ & $p$ \\
\hline Gender & & & & \\
Male & 3.57 & .52 & -1.35 & .18 \\
Female & 3.68 & .43 & & \\
Age & & & & \\
$\quad$ Younger & 3.62 & .47 & -.33 & .74 \\
$\quad$ Older & 3.65 & .47 & & \\
\hline
\end{tabular}

Internet for news on any device", and "search for information with a mobile phone".

The last section was new media literacy. The researchers adopted new media literacy scale for university students developed and validated by Koc and Barut [25]. The 35item scale included four sub-scales: 7 items for Functional Consumption (e.g. It is easy for me to make use of various media environments to reach information), 11 items for Critical Consumption (e.g. I can evaluate media in terms of legal and ethical rules), 7 items for Functional Prosumption (e.g. I can use hardware necessary for developing media contents), and 10 items for Critical Prosumption (e.g. I am skilled at designing media contents that reflect critical thinking of certain matters). All scales were measured with a 5-point Likert-type scale $(1=$ Strongly disagree to $5=$ Strongly agree). The sub-scales originally have a good internal consistency, with a Cronbach's Alpha coefficient reported of .85 (Functional Consumption), .87 (Critical Consumption), .89 (Functional Prosumption), and .93 (Critical Prosumption).

In the current study, a pilot test was conducted for 20 respondents to ensure its internal consistency and they understand the questions. Cronbach's Alpha coefficient of a scale is ideally above .7 [26]. Although the Cronbach's Alpha coefficient of the sub-scales of new media literacy in the current study were lower than of Koc and Barut [25], they were still above .7 as shown in Table 1. 
International Conference on Recents Advancements in Engineering and Technology (ICRAET-18) |15th and 16th March 2019|Siddhartha Institute of Technology \& Sciences, Telangana, India.

Table 4: One-Way Analysis of Variance of New Media Literacy by Media Use

\begin{tabular}{lccccc}
\hline \multicolumn{1}{c}{ Source } & df & SS & MS & $F$ & $p$ \\
\hline $\begin{array}{l}\text { Between } \\
\text { groups }\end{array}$ & 2 & 2594.84 & 1297.42 & 5.17 & .007 \\
$\begin{array}{l}\text { Within } \\
\text { groups }\end{array}$ & 124 & 31131.97 & 251.06 & & \\
Total & 126 & 33726.80 & & & \\
\hline
\end{tabular}

Table 5: Pearson Product-Moment Correlations between Media Use and New Media Literacy

\begin{tabular}{lccccc}
\hline Measures & 1 & 2 & 3 & 4 & 5 \\
\hline MU & - & & & & \\
FC & .097 & - & & & \\
CC & .169 & $.617^{* *}$ & - & & \\
FP & $.259^{* *}$ & $.681^{* *}$ & $.568^{* *}$ & - & \\
CP & $.179^{*}$ & $.470^{* *}$ & $.473^{* *}$ & $.469^{* *}$ & - \\
\hline
\end{tabular}

$\mathrm{MU}=$ Media Use, $\mathrm{FC}=$ Functional Consumption, $\mathrm{CC}=$ Critical Consumption, FP = Functional Prosumption, $\mathrm{CP}=$ Critical Prosumption

$\mathrm{N}=128$.

${ }^{*} p<.05 .{ }^{* *} p<.001$.

\section{Analysis}

In this study, data was analyzed using IBM SPSS Statistics 21 software. Apart from descriptive analysis for demographics, t-test was conducted to test $\mathrm{H} 1$ and $\mathrm{H} 2$. As for RQ2, One-way Analysis of Variance (ANOVA) was used to test $\mathrm{H} 3$ and Pearson Correlation to test H4.

\section{RESULTS AND FINDINGS}

\section{A. New Media Literacy Level}

Table 2 displays the different levels of new media literacy among the university students. More than half of the respondents $(61.7 \%)$ are at the medium level of media literacy, followed by high level (32\%). Only $6.3 \%$ of the respondents are at the low level.

B. Difference in New Media Literacy across Demographic Factors

In Table 3, an independent-samples t-test was conducted to compare the new media literacy for males and females. There was no significant difference in new media literacy for males $(\mathrm{M}=3.57, \mathrm{SD}=.52)$ and females $[\mathrm{M}=3.68, \mathrm{SD}=.43$; $t(126)=-1.35, p=.18]$. The magnitude of the difference in the means was very small (eta squared=.01). Therefore, the results did not show support for $\mathrm{H} 1$.

Likewise, the similar test was conducted to compare the new media literacy for younger and older groups, there was also no significant difference in new media literacy for younger $(\mathrm{M}=3.62, \mathrm{SD}=.47)$ and older $[\mathrm{M}=3.65, \mathrm{SD}=.47$; $\mathrm{t}(126)=-.33, \mathrm{p}=.74]$. The magnitude of the difference in the means was very small (eta squared=.00). Therefore, $\mathrm{H} 2$ was rejected.

\section{Difference in New Media Literacy by Media Use}

Table 4 shows a one-way between-groups analysis of variance was conducted to explore the impact of media use on levels of new media literacy. Subjects were divided into three groups based on the levels of media use (Group 1: Low; Group 2: Medium; Group 3: High). There was a statistically significant difference at the $p<.05$ level in new media literacy scores for the three groups of media use $[\mathrm{F}(2$, 124) $=5.2, \mathrm{p}=.007]$. Calculated using eta squared, the effect size was medium (.07). Post-hoc comparisons using the Tukey HSD test indicated that the mean score for Group 1 $(\mathrm{M}=123.75, \mathrm{SD}=12.18)$ was not significantly different from Group $2(\mathrm{M}=125.18, \mathrm{SD}=16.77)$ but differed significantly from Group 3 (M=136.77, $\mathrm{SD}=15.01)$. Group 2 also differed significantly from Group 3. Therefore, H3 was supported.

\section{Relationship between Media Use and New Media} Literacy

The relationships between media use and media literacy by dimensions were investigated using Pearson productmoment correlation coefficient as presented in Table 5. There was a small positive correlation between media use with functional prosumption $[\mathrm{r}=.26, \mathrm{n}=127, \mathrm{p}<.01]$, with high level of media use associated with higher level of functional prosumption. Likewise, another small positive correlation was also found between media use and critical prosumption [ $\mathrm{r}=.18, \mathrm{n}=127, \mathrm{p}<.05]$, with high level of media use associated with higher level of critical prosumption. The other two dimensions, functional consumption and critical consumption, did not show relationship with media use. With that said, the results did not support $\mathrm{H} 4$.

\section{DISCUSSION AND CONCLUSION}

Overall, most of the respondents were at the medium level of new media literacy. This study did not show significant difference in new media literacy across demographic factors. Gender did not differ significantly in new media literacy, this is in line with the finding from Balaban-Sali [9]. Although the purposes that young males use social media for are different from that of young females [27], but both spend a lot of time on new media environment and develop media literacy, therefore no significant difference was found between male and female. Age wise, the sample in this study was university students with a short age range from 18 to 25 , this could contribute to the unnoticeable difference between the younger and older group of respondents.

Based on the findings, new media literacy varies across different levels of media use. People who seldom use media directly show low access to media content. Without exposing to the abundance of online news and information which could be false or misleading, they will not be motivated to look for the truth. They are also less likely turn to online source to find information to evaluate any news they receive from others. In other words, low media use limits the ability to analyze and evaluate information. Besides, people will not create media content when they seldom use new media which enable people to produce own media content. Therefore there is a significant difference in new media literacy between low and high media users.

However, media use only shows a positive relationship with two prosuming dimensions of new media literacy, which are functional prosumption and critical prosumption. This shows that the more they use new media, the higher the ability to create and share media content, such as writing 
articles and blog, as well as developing video which can include critical reviews on the current issue from different perspectives. Besides, higher media users are more likely to participate in online group discussion and give comments. Nonetheless, the strength of the relationship between media use and functional prosumption and critical prosumption was small.

\section{A. Implications}

Countering fake news requires critical thinking, evaluation and judgment of the public who used to be the victims of misleading information. The findings of this study serve as a valuable input for public and private institutions that are keen or responsible in tackling fake news. It also contributes to the body of knowledge on new media literacy in Malaysia; other local and foreign researchers can use the information for future research on media literacy.

\section{B. Limitations and Future Recommendations}

As this is a preliminary study with a small sample size, the findings of the research did not achieve generalization of the whole population in Malaysia. Besides, small age range is difficult to discover the difference in new media literacy based on age factor. In future, researchers are suggested to consider a larger sample size and extend the sample from students to general public, therefore a wide range of age can be obtained, other demographic factors such as education level, income, marital status which are not able to be measured within a sample of students can also be studied. Apart from that, the scale adopted from Koc and Barut [25] can be factor analyzed to ensure items with higher factor loading to be retained in order to better measure the new media literacy in the local context. Lastly, it is suggested to study whether media literacy can motivate people to solve fake news problems through communicative actions.

\section{REFERENCES}

1. Chang C, Liu E, Lee C-Y, Chen N-S, Hu DC, Lin C-H. Developing and validating a media literacy selfevaluation scale (MLSS) for elementary school students. The Turkish Online Journal of Educational Technology. 2011;10(2):63-71.

2. Boczkowski P, Mitchelstein E, Matassi M. Incidental news: How young people consume news on social media. Prceedings of the 50th Hawaii International Conference on System Sciences. 2017.

3. Newman N, Fletcher R, Kalogeropoulos A, Levy DAL, Nielsen RK. Reuters institute digital news report 2018. 2018.

4. Raj PS. Media literacy is critical The Star Online. 2019 29 January.

5. Aldwairi M, Alwahedi A. Detecting fake news in social media networks. Procedia Computer Science. 2018;141:215-22.

6. Zanuddin $\mathrm{H}$, Watimin NH. Managing crisis and response time analysis: Effectiveness of online monitoring strategy analysis. The European Proceedings of Social \& Behavioral Sciences. 2018;XL:157-77.

7. El Rayess M, Chebl C, Mhanna J, Hage R-M. Fake news judgement: The case of undergraduate students at Notre Dame University-Louaize, Lebanon. Reference Services Review. 2018;46(1):146-9.
8. Feuerstein M. Media literacy in support of critical thinking. Journal of Educational Media. 1999;24(1):4354.

9. Balaban-Sali J. New media literacy of communication students. Contemporay Educational Technology. 2012;3(4):265-77.

10. Baharuddin MF. Digital literacy awareness among students. Research Hub. 2016;2(1):57-63.

11. Tenku Shariman T, Talib O, Ibrahim N, editors. The relevancy of digital literacy for Malaysian students for learning with Web 2.0 technology2014.

12. Chen D-T, Wu J, Wang Y-M. Unpacking new media literacy. Journal of Systemics, Cybernetics and Informatics. 2011;9(2):84-8.

13. Chen D-T, Lin T-B, Li J-Y, Lee L. Establishing the norm of new media literacy of Singaporean students: Implications to policy and pedagogy. Computers \& Education. 2018;124:1-13.

14. Aufderheide P. Media literacy: A report of the national leadership conference on media literacy. Washington, DC: Aspen Institue1993.

15. Buckingham $D$. The media literacy of children and young people: A review of the research literature. London: Ofcom; 2005.

16. Literat I. Measuring new media literacies: Towards the development of a comprehensive assessment tool Journal of Media Literacy Education. 2014;6(1):15-27.

17. Potter WJ. The state of media literacy. Journal of Broadcasting \& Electronic Media. 2010;54(4):675-96.

18. Potter WJ. Theory of media literacy: A cognitive approach. Thousand Oaks, CA: Sage; 2004.

19. Boyd MJ, Dobrow J. Media literacy and positive youth development. In: Lerner RM, Lerner JV, Benson JB, editors. Advances in child development and behavior. 41: JAI; 2011. p. 251-71.

20. Davidsone A, Silkane V, editors. The relationship between media literacy and civic participation among young adults in Latvia. Information Literacy in Everyday Life; 2019; Cham: Springer International Publishing.

21. Jenkins H, Clinton K, Purushatma R, Robison A, Weigel M. Confronting challenges of participatory culture: Media education for the 21 st century. Chicago, IL: MacArthur Foundation; 2006

22. Miocic B, Perinić J. New media literacy skills of youth in Zadar. Medijska Istrazivanja. 2014;20(2):231-55.

23. Arsenijević J, Andevski M. New media literacy within the context of socio-demographic characteristics. Procedia Technology. 2016;22:1142-51.

24. Rosen LD, Whaling K, Carrier LM, Cheever NA, Rokkum J. The media and technology usage and attitudes scale: An empirical investigation. Computers in human behavior. 2013;29(6):2501-11.

25. Koc M, Barut E. Development and validation of New Media Literacy Scale (NMLS) for university students. Computers in Human Behavior. 2016;63:834-43.

26. Pallant J. SPSS survival manual: A step by step guide to data analysis using SPSS. 4th ed. Maidenhead: Open University Press/McGraw-Hill; 2010.

27. Syn SY, Oh S. Why do social network site users share information on Facebook and Twitter? Journal of Information Science. 2015;41(5):553-69. 
International Conference on Recents Advancements in Engineering and Technology (ICRAET-18) |15th and 16th March 2019|Siddhartha Institute of Technology \& Sciences, Telangana, India.

\section{AUTHORS PROFILE}

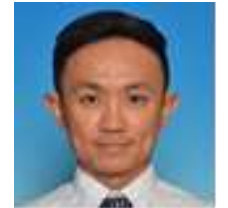

Chin Ying Shin $\mathrm{He}$ obtained Bachelor of Communication in Persuasive Communication at Universiti Sains Malaysia and Master of Arts in Communications at Universiti Malaysia Sabah. Currently he is pursuing PhD studies at University of Malaya. He is also a lecturer at the Department of Public Relations, Faculty of Arts and Social Science, Universiti Tunku Abdul Rahman, Kampar Campus, Perak, Malaysia. His research interests include media and communication studies, cultivation analysis, fake news, and situational theory of problem solving (STOPS).

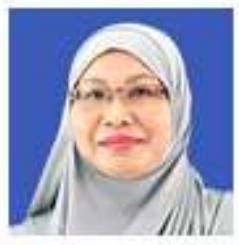

Hasmah Zanuddin PhD University of Westminster, London, Associate Professor at the Department of Media Studies, Faculty of Arts and Social Sciences, University of Malaya, Kuala Lumpur, Malaysia. Her expertise includes Public Relations, Media \& Communication Policy \& Management, Research Method, Content Studies and Audience Research. She has vast experience in research collaborations at the national and international level such as the Korean-Australian Research Center, University of New South Wales, Australia.. Her academic works were published in books, book chapters and journal articles. She stays active as the Working Committee to the Social Development Cluster of the Majlis Profesor Negara (MPN) and a member to the Working Committee for the Social Council led by the Implementation, Coordination Unit (ICU) Prime Minister's Department, Malaysia. 